\title{
Shared Decision Making and Effective Physician-Patient Communication: The Quintessence of Patient-Centered Care
}

\author{
Huy Ming Lim, ${ }^{1}$ Kristiana Siste Kurniasanti. ${ }^{2}$
}

"The good physician treats the disease; the great physician treats the patient who has the disease."

-Sir William Osler

The Institute of Medicine's (IOM) 2001 landmark report, Crossing the Quality Chasm: A New Health System for the 21st Century, identified patient-centeredness as one of the fundamental attributes of quality health care, alongside safety, effectiveness, timeliness, efficiency, and equity. 'The IOM defined patient-centeredness as "providing care that is respectful of and responsive to individual patient preferences, needs, and values and ensuring that patient values guide all clinical decisions." "This concept of patient-centered care represents a paradigm shift from the traditional disease-oriented and physician-centered care, grounding health care in the subjective experience of illness and the needs and preferences of individual patients rather than the evaluation and treatment of diseases which emphasizes on leveraging clinical expertise and evidence derived from population-based studies.

A multiyear research conducted by the Picker Commonwealth Program for Patient-Centered Care (now the Picker Institute), which coined the term "patient-centered care" in 1987, revealed that patient-centered care encompasses seven dimensions from the patient perspective: (1) respect for patients' values, preferences, and expressed needs; (2) coordination and integration of care; (3) information, communication, and education; (4) physical comfort; (5) emotional support and alleviation of fear and anxiety; (6) involvement of family and friends; and (7) transition and continuity of care. ${ }^{2}$ This conceptual framework transcends the earlier interpretations of patient-centeredness as a way of how physicians should interact and communicate with patients at the interpersonal level, expanding the concept to the health care system level. ${ }^{3}$ Since the inception of the patient-centered care concept, a plethora of studies have repeatedly shown that orienting health care around the needs and preferences of patients holds promise for improved health care quality, patient satisfaction, and health outcomes. ${ }^{4-8}$

At the pinnacle of patient-centered care is shared decision making, a process by which clinicians and patients participate jointly in making health decisions for a preference-sensitive condition-a condition where more than one screening, diagnosis, in- tervention, or support strategy is clinically appropriate. ${ }^{9,10}$ Shared decision making goes beyond the discussion of risks and benefits involved in the informed consent process. ${ }^{11}$ It also helps identify and takes into consideration the patient's circumstances, values, and informed preferences for the risks, benefits, and uncertainties associated with each alternative. This is in sharp contrast to the traditional decision-making approach, in which clinicians make decisions for rather than with patients. Shared decision making recognizes that both clinicians and patients bring different but equally important forms of expertise to the table. The extent to which a clinician or a patient takes responsibility for the decision-making process varies in different circumstances along a continuum between two extremes: clinician-driven decision making and patient-driven decision making. ${ }^{12}$

Shared decision making is only attainable in the presence of effective physician-patient communication. In fact, quality communication within the physician-patient dyad is the single most important enabler of quality health care, without which the delivery of patient-centered care would not be possible. ${ }^{13}$ Clear, respectful, and empathic communication between health care professionals and patients enables and supports information exchange, shared decision making, management of uncertainties and emotions, patient self-management, and meaningful clinician-patient relationship. ${ }^{14}$ Successful integration of these functions leads to increased access to care, greater patient knowledge and shared understanding, enhanced therapeutic alliances, better management of emotions, improved family and social support, enhanced patient empowerment and agency, and higher quality health decisions, which, in turn, improve patient satisfaction, treatment adherence, physical and emotional well-being, and health outcomes. ${ }^{14-18}$ In contrast, gaps or lapses in physician-patient communication can lead to medical errors and undesirable outcomes. ${ }^{19,20}$

The experience articles by DiSalvo in this issue of International Journal of Medical Students (IJMS) present the perspectives and experiences of a medical student with regard to patient-centered care as he engaged in the care process of patients as part of his clinical training. The first article explores the importance of patient-centered communication and shared decision making through his experience with a chronic liver failure patient. ${ }^{21}$ The patient was loaded with physical and emotional discomforts

${ }^{1}$ Deputy Editor of the International Journal of Medical Students (IJMS). Universitas Indonesia, Jakarta, Indonesia.

2Department of Psychiatry, Cipto Mangunkusumo National Referral Hospital, Faculty of Medicine, Universitas Indonesia, Jakarta, Indonesia 
owing to lapses in physician-patient communication, a deficient coordination and transition of care, and a lack of attention to the patient's physical and emotional needs. The second article discusses the significance of treating patients as individuals and incorporating patients' values and preferences into clinical practice through his reflection on the meaning of the "First, do no harm" aphorism as he followed up a critically injured patient who was unable to decide for himself. ${ }^{22}$ In both cases, paternalistic physicians made health decisions for the patients without adequate communication with the patients or their families and friends.

DiSalvo's experiences add to the growing body of evidence that there is inadequate physician-patient communication and little shared decision making taking place in clinical practice, despite the universal recognition of patient-centered care as the desideratum of health care. Many physicians feel that they actively engage patients in the decision-making process and communicate effectively with their patients, but evidence suggests a perception-reality gap and a discrepancy between patient's and physicians' impressions about the care received or provided. ${ }^{23,24} \mathrm{As}$ a consequence, decades after the publication of the first compelling evidence to support patient-centered care, ${ }^{25}$ paternalism continues to dominate health decision making, and the primacy of patients' preferences and expressed needs remains to be appreciated in most clinical encounters. ${ }^{26-28}$

A number of reasons may account for the limited adoption of shared decision making in clinical practice. Most clinicians cite time constraints, lack of applicability due to patient characteristics, and lack of applicability due to the clinical situation as the most important barriers to engaging patients in the decision-making process. ${ }^{29}$ These perceived barriers likely represent misconceptions about shared decision making. ${ }^{30}$ Current evidence indicates that implementation of shared decision making does not result in a systematic increase in consultation duration. ${ }^{31}$ Additionally, regardless of their education and functional health literacy, all patients want to be involved in health decision making, albeit with different levels of engagement. ${ }^{32}$ Therefore, even the most vulnerable patients should not be systematically excluded from shared decision making. Other misconceptions which hamper the implementation of shared decision making include misconceptions about the nature of shared decision making, the incompatibility of shared decision making with evidence-based practice, and the degree to which patients wish to share in decision making. ${ }^{30}$

In contrast to clinician-reported factors which reflect clinicians' presumptions that many patient will not benefit from shared decision making or do not wish to take part, patients reported a multitude of barriers which limit their capacity to participate in shared decision making. These patient-reported barriers include inadequate information provision, lack of continuity of care, inadequate environmental conditions, interpersonal characteristics of the clinicians, medical terminology used by clinicians, and a power imbalance in the physician-patient relationship. ${ }^{33}$ The power imbalance between clinicians and patients causes patients to undervalue their knowledge and expertise relative to that of clinicians and adopt a passive and compliant role out of the fear of being labeled as "difficult" patients.33,34 Additionally, patient perceptions of shared decisions may differ from physician perceptions of shared decisions. ${ }^{35,36}$
Understanding patient perceptions of shared decision making and barriers to its implementation is particularly important, as only patient-reported shared decision making is significantly and positively associated with improved patient outcomes. ${ }^{37}$

While the major obstacles to the implementation of shared decision making are misconceptions about shared decision making, organizational factors, and factors associated with decision-making interactions, inadequate physician-patient communication is largely attributable to the lack of emphasis on communication skills in medical training. Most communication training takes place during the preclinical years of undergraduate medical education in the form of lectures and role plays with standardized patients. In the clerkship years, at a time when students have direct encounters with patients and communication skills are most crucial, little attention is devoted to communication training. The teaching of diagnostic skills and patient management takes the central stage. Rarely do students receive specific instruction or feedback regarding their interactions with patients. Similarly, communication skills are often not addressed in postgraduate medical training, leaving residents and practicing physicians to learn communication skills on their own. Additionally, physicians cite time pressures as a significant barrier to establishing effective communication with patients, as listening to patients, addressing their needs and emotional concerns, and helping them make decisions that are consistent with their values and preferences all require time..$^{38-40}$

To successfully achieve the provision of patient-centered care and improve the quality of health care, critical barriers to shared decision making and effective physician-patient communication must be addressed. A number of effective interventions directed at clinicians and patients have been developed for this purpose. ${ }^{41}$ Well-designed training programs for clinicians have been shown to be effective in transferring patient-centered skills to clinicians, leading to significant increases in the patient-centeredness of consultation processes. ${ }^{42}$ Decision aids, on the other hand, improve patients' knowledge and risk perceptions, promote their active participation in decision making, and reduce their internal decisional conflict related to feeling uninformed and unclear about their personal values. ${ }^{31}$ Various other patient engagement strategies have also been developed and proved to be effective in improving health literacy, helping patients make appropriate health decisions, and improving the quality of care process. ${ }^{43}$ These findings are encouraging. Nonetheless, a genuinely patient-centered care would not be possible if power imbalances, either perceived or real, continue to exist in the physician-patient relationship. Interventions must be developed to redress these power imbalances to facilitate shared decision making and effective communication between physicians and patients.

Patient-centered care is the answer to the health care reform necessitated by today's increasingly complex and fragmented health care delivery system. A paradigm shift towards patient-centered care promises many potential gains, including improved health care quality and safety, increased patient satisfaction and adherence to treatment plans, improved health outcomes, and reduced health care cost. Regrettably, despite the ubiquitous talk about patient-centered care in modern health care, shared decision-making and effective physician-patient communication-the two cruxes of patient-centered care-are 


\section{Editorial}

yet to become the norms. Strategies to promote and enhance shared decision-making and effective communication between clinicians and patients should be rigorously implemented to establish a health care system that truly values patients as individuals and turn the rhetoric of patient-centered care into reality.

\section{References}

1. Institute of Medicine, Committee on Quality of Health Care in America. Crossing the quality chasm: a new health system for the 21st century. Washington, DC: National Academy Press; 2001.

2. Certeiss M, Edgman-Levitan S, Daley J, Delbanco TL, editors. Through the patient's eyes: understanding and promoting patient-centered care. San Francisco (CA): Jossey-Bass; 1993. 3. Saha S, Beach MC, Cooper LA. Patient centeredness, cultural competence and healthcare quality. J Natl Med Assoc. 2008 Nov;100(11):1275-85.

4. Rathert C, Wyrwich MD, Boren SA. Patient-centered care and outcomes: a systematic review of the literature. Med Care Res Rev. 2013 Aug;70(4):351-79. 5. McMillan SS, Kendall E, Sav A, King MA, Whitty JA, Kelly F, et al. Patient-centered approaches to health care: a systematic review of randomized controlled trials. Med Care Res Rev. 2013 Dec;70(6):567-96.

6. Weiner SJ, Schwartz A, Sharma G, Binns-Calvey A, Ashley N, Kelly B, et al. Patient-centered decision making and health care outcomes: an observatio nal study. Ann Intern Med. 2013 Apr 16;158(8):573-9.

7. Nelson KM, Helfrich C, Sun H, Hebert PL, Liu CF, Dolan E, et al. Implementation of the patient-centered medical home in the veterans health administration: associations with patient satisfaction, quality of care, staff burnout, and hospital and emergency department use. JAMA Intern Med. 2014 Aug;174(8):1350-8. 8. Kern LM, Edwards A, Kaushal R. The patient-centered medical home, electronic health records, and quality of care. Ann Intern Med. 2014 Jun 3;160(11):741-9. 9. Barry MJ, Edgman-Levitan S. Shared decision making - the pinnacle of patient-centered care. N Engl J Med. 2012 Mar 1;366(9):780-1.

10. Coulter A, Collins A. Making shared decision-making a reality: no decision about me, without me. London: The King's Fund; 2011.

11. Shafir A, Rosenthal J. Shared decision making: advancing patient-centered care through state and federal implementation. Portland (ME): National Academy for State Health Policy; 2012.

12. Kon AA. The shared decision-making continuum. JAMA. 2010 Aug 25;304(8):903-4. 13. American Medical Association, Ethical Force ProgramTM Oversight Body. An Ethical Force ProgramTM consensus report: improving communicationimproving care. Chicago (IL): American Medical Association; 2006.

14. Street RL Jr, Makoul G, Arora NK, Epstein RM. How does communication heal? Pathways linking clinician-patient communication to health outcomes. Patient Educ Couns. 2009 Mar;74(3):295-301.

15. White RO, Eden S, Wallston KA, Kripalani S, Barto S, Shintani A, et al. Health communication, self-care, and treatment satisfaction among low-income diabetes patients in a public health setting. Patient Educ Couns. 2015 Feb;98(2):144-9. 16. Zolnierek KB, DiMatteo MR. Physician communication and patient adherence to treatment: a meta-analysis. Med Care. 2009 Aug;47(8):826-34.

17. Priebe S, McCabe R, Bullenkamp J, Hansson L, Lauber C, Martinez-Leal R, et al. Structured patient-clinician communication and 1 -year outcome in community mental healthcare: cluster randomised controlled trial. Br J Psychiatry. 2007 Nov; 191(5):420-6. 18. Trummer UF, Mueller UO, Nowak P, Stidl T, Pelikan JM. Does physician-patient communication that aims at empowering patients improve clinical outcome? A case study. Patient Educ Couns. 2006 May;61(2):299-306.

19. Mira JJ, Orozco-Beltrán D, Pérez-jover V, Martínez-Jimeno L, Gil-Guillén VF, Carratala-Munuera C, et al. Physician patient communication failure facilitates medication errors in older polymedicated patients with multiple comorbidities. Fam Pract. 2013 Feb;30(1):56-63.
20. Colloca L, Finniss D. Nocebo effects, patient-clinician communication, and therapeutic outcomes. JAMA. 2012 Feb 8;307(6):567-8.

21. DiSalvo DS. A medical student experience: adding value and emotional support to patient interactions. Int J Med Students. 2014 Nov-2015 Mar;3(1):63-4. 22. DiSalvo DS. The meaning of "do no harm": a medical student perspective. Int J Med Students. 2014 Nov-2015 Mar;3(1):65-6.

23. Couët N, Desroches S, Robitaille $H$, Vaillancourt $H$, Leblanc A, Turcotte S, et al. Assessments of the extent to which health-care providers involve patients in decision making: a systematic review of studies using the OPTION instrument. Health Expect. 2013 Mar 4. 24. Olson DP, Windish DM. Communication discrepancies between physicians and hospitalized patients. Arch Intern Med. 2010 Aug 9;170(15):1302-7. 25. Greenfield S, Kaplan S, Ware JE Jr. Expanding patient involvement in care. Effects on patient outcomes. Ann Intern Med. 1985 Apr;102(4):520-8.

26. Fowler FJ Jr, Gerstein BS, Barry MJ. How patient centered are medical decisions? Results of a national survey. JAMA Intern Med. 2013 Jul 8;173(13):1215-21. 27. Hesselink G, Flink M, Olsson M, Barach P, Dudzik-Urbaniak E, Orrego C, et al. Are patients discharged with care? A qualitative study of perceptions and experiences of patients, family members and care providers. BMJ Qual Saf. 2012 Dec;21(Suppl 1):i39-49. 28. Heyland DK, Barwich D, Pichora D, Dodek P, Lamontagne F, You JJ, et al. Failure to engage hospitalized elderly patients and their families in advance care planning. JAMA Intern Med. 2013 May 13;173(9):778-87.

29. Légaré F, Ratté S, Gravel K, Graham ID. Barriers and facilitators to implementing shared decision-making in clinical practice: update of a systematic review of health professionals' perceptions. Patient Educ Couns. 2008 Dec;73(3):526-35. 30. Légaré $F$, Thompson-Leduc P. Twelve myths about shared decision making. Patient Educ Couns. 2014 Sep;96(3):281-6.

31. Stacey D, Légaré F, Col NF, Bennett CL, Barry MJ, Eden KB, et al. Decision aids for people facing health treatment or screening decisions. Cochrane Database Syst Rev. 2014 Jan 28;1:CD001431.

32. Smith SK, Dixon A, Trevena L, Nutbeam D, McCaffery KJ. Exploring patient involvement in healthcare decision making across different education and functional health literacy groups. Soc Sci Med. 2009 Dec;69(12):1805-12.

33. Joseph-Williams N, Elwyn G, Edwards A. Knowledge is not power for patients: a systematic review and thematic synthesis of patient-reported barriers and facilitators to shared decision making. Patient Educ Couns. 2014 Mar;94(3):291-309. 34. Frosch DL, May SG, Rendle KA, Tietbohl C, Elwyn G. Authoritarian physicians and patients' fear of being labeled 'difficult' among key obstacles to shared decision making. Health Aff. 2012 May;31(5):1030-8.

35. Shay LA, Lafata JE. Understanding patient perceptions of shared decision making. Patient Educ Couns. 2014 Sep;96(3):295-301.

36. Fiks AG, Hughes CC, Gafen A, Guevara JP, Barg FK. Contrasting parents' and pediatricians' perspectives on shared decision-making in ADHD. Pediatrics. 2011 Jan;127(1):e188-96. 37. Shay LA, Lafata JE. Where is the evidence? A systematic review of shared decision making and patient outcomes. Med Decis Mak. 2015 Jan;35(1):114-31. 38. Levinson W, Pizzo PA. Patient-physican communication: it's about time. JAMA. 2011 May 4;305(17):1802-3.

39. Levinson W, Lesser CS, Epstein RM. Developing physician communication skills for patient-centered care. Health Aff. 2010 Jul;29(7):1310-8.

40. Levinson W. Patient-centred communication: a sophisticated procedure. BMJ Qual Saf. 2011 Oct;20(10):823-5.

41. Légaré F, Turcotte S, Stacey D, Ratté S, Kryworuchko J, Graham ID. Patients perceptions of sharing in decisions: a systematic review of interventions to enhance shared decision making in routine clinical practice. Patient. 2012;5(1):1-19. 42. Dwamena F, Holmes-Rovner M, Gaulden CM, Jorgenson S, Sadigh G, Sikorskii A, et al. Interventions for providers to promote a patient-centred approach in clinical consultations. Cochrane Database Syst Rev. 2012 Dec 12;12:CD003267. 43. Coulter A. Patient engagement-what works? J Ambul Care Manage. 2012 Apr-Jun;35(2):80-9.

\section{Acknowledgments}

None.

Conflict of Interest Statement a Funding

The Authors has no funding, financial relationships or conflicts of interest to disclose.

Cite as:

Lim HM, Kurniasanti KS. Shared Decision Making and Effective Physician-Patient Communication: The Quintessence of Patient-Centered Care. Int J Med Students. 2014 Nov-2015 Mar;3(1):7-9. 